\title{
Interactive comment on "Impacts of black carbon and mineral dust on radiative forcing and glacier melting during summer in the Qilian Mountains, northeastern Tibetan Plateau" by Y. Li et al.
}

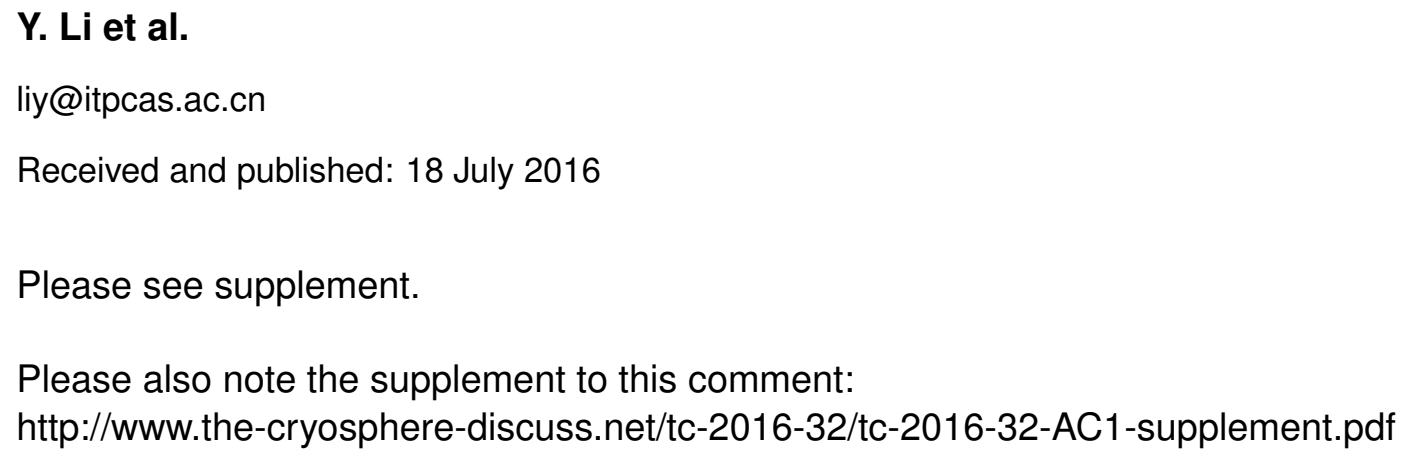

